Methods The GTF game design competition consisted of participants firstly submitting their ideas for an online sexual health education game using a game design document. Following this, willing participants took part in a two-day game jam which resulted in the game prototype for Infection Protection chosen as the winning entry. The winning team were contracted to build the game suitable for both a desktop and a mobile device as well as to finalise it to a standard that was suitable for the GTF website.

Results Infection Protection educates young people on the risk of STI transmission from having unsafe sex with multiple partners. It also demonstrates the simplicity of getting tested and treated for STIs. The game uses a simulation of characters engaging in sex with each other. The user is required to check characters for medical updates, provide safe sex packs, and send characters to the clinic for testing and treatment.

Conclusion The GTF game design competition involved young people in the planning and development of a peer-based resource, and was an innovative way to educate participants on sexual health. Further conclusions on the effectiveness of the game will be presented when preliminary evaluation data is obtained from Google Analytics and the target audience.

Disclosure of interest statement This paper is supported and funded by the WA Department of Health.

\section{P03.23 HUMAN IMMUNODEFICIENCY VIRUS INFECTION RISK BEHAVIOURS AMONG SCHOOL STUDENTS IN THE CAPITAL CITY OF A FAMOUS TRAVEL DESTINATION, BALI}

NW Septarini*, Igbk Raharja. School of Public Health, Faculty of Medicine, Udayana University, Bali, Indonesia

\subsection{6/sextrans-2015-052270.251}

Introduction HIV (Human Immunodeficiency Virus) infection remains an international health problem. Denpasar, a capital city of one of a famous tourist destination in the world was contributing the largest of AIDS cases in Bali-Indonesia. Based on the Bali Provincial AIDS Commission report, most of PLWHA in Bali are between age 20-29 years old. It can be assumed that the HIV infection occurred 5-10 years before which is around 10-15 years old of age when they were in junior/senior high school. This study aimed to recognise the HIV risk behaviours among school students in Denpasar.

Methods This is cross-sectional descriptive survey involving 297 junior high school students which are selected using cluster random sampling method. This survey took place in two state junior high schools and six private junior high schools in Denpasar. Data were collected using self administered anonymous questionnaire.

Results The results found $1 \%$ students have ever used illicit drugs, $1 \%$ students have ever injected drugs, $6 \%$ students have pierced, and $0.7 \%$ students have permanent tattoo. The result also implied that $5 \%$ of students had sexual intercourse and only $61.5 \%$ who always using condom and $15 \%$ never use condom. Overall, $10 \%$ of respondents were practicing HIV risk behaviours. The other findings shows males have odd 9.297 of doing sexual intercourse than women $(\mathrm{p}=0.001)$. Interestingly, it also found that students who used injection drugs have odd 10.808 for sexual intercourse than students who never used injection drugs $(\mathrm{p}=0.019)$.

Conclusion It can be conclude that even only $10 \%$ of risky behaviour on HIV infection, it seem that all relevant parties need to pay attention including for junior high school students as one of the vulnerable groups on the spread of HIV and AIDS. The attention could be by performing effective promotive and preventive actions.

Disclosure of interest statement There is nothing to be declare.

\section{P03.24 EFFECT OF MEDIA ON ADOLESCENT GIRLS "HIVIAIDS COMPREHENSIVE KNOWLEDGE" AND "STIGMATISING ATTITUDE" TOWARDS PEOPLE LIVING WITH HIVIAID}

Deepak Sharma*. Post Graduate Institute of Medical Education and Research, School of Public Health, Chandigarh, India

\subsection{6/sextrans-2015-052270.252}

Background Mass media is an important educational tool for increasing knowledge of HIV and fighting stigmatisation associated with it in the society.

Objectives This study aimed at assessing the "comprehensive knowledge" on HIV/AIDS among the adolescent's girls in India. The second objective was to understand how mass media influences knowledge and stigmatising attitude towards people living with HIV/AIDS.

Methods Secondary data analysis was done for the data available from the third round of the National Family Health Survey of India (NFHS-3). "Comprehensive knowledge" was defined as an individual who knew a) using a condom and having just one uninfected partner limits the risk of getting AIDS b) a healthy looking person can have AIDS and rejected the two most common misconceptions about AIDS transmission (transmission by mosquito bites and by sharing food). Stigmatising attitude included questions like, "if a teacher has HIV/AIDS but not sick, should he/she be allowed to continue teaching in school". Media sources included broadcast media (TV programs/radio), print media (newspapers/display hoardings) and interpersonal sources (family/friends/health workers/community leaders). All data was analysed using the Statistical Package for the Social Sciences software. Descriptive statistics was used to examine the study subject's exposure to mass media, knowledge about HIV/AIDS, and its sources of knowledge. In the process of analysis, logistic regression model was used to observe how mass media influences knowledge and stigmatising attitude towards people living with HIV/AIDS after controlling for confounders.

Results $64.3 \%$ had ever heard about HIV/AIDS. The most common source of information about HIV/AIDS were broadcast media $(88.5 \%)$ followed by interpersonal communication $(50.7 \%)$ and print media (33\%). Exposure to sources of HIV information was significantly related to HIV knowledge (OR = 4.5 for broadcast group; $\mathrm{OR}=2.9$ for print media and $\mathrm{OR}=$ 1.2 for interpersonal group) and less stigmatising attitude towards PLWHA (OR $=1.8$ for broadcast group; $\mathrm{OR}=2.2$ for print media and $\mathrm{OR}=0.9$ for interpersonal group).

Conclusions Exposure to mass media can help increase HIV/ AIDS knowledge of adolescent girls. Enhancing its penetration in public can be an important strategy in disseminating HIV knowledge and reducing HIV related discrimination in India. 